\title{
Os desafios motivacionais na gestão dos profissionais de TI: estudo de três empresas*
}

\section{Motivational challenges in the management of IT professionals: study of three companies}

Paulo Rogério Foina ${ }^{1}$ Victor Luis de Lauro Eiras ${ }^{2}$
Recebido em: 09/01/2016. Aprovado em: 10/04/2016.

1 Físico e doutor em informática. Consultor de empresas. Coordenador de cursos de graduação e pós-graduação em TIC.

2 Graduando do curso de Ciências da Computação do Centro Universitário de Brasília - UniCEUB.

\section{Resumo}

A fácil adaptação a diversos ambientes e a busca pelo desenvolvimento de soluções inovadoras fez dos profissionais da área de tecnologia da informação peças fundamentais para a continuidade das empresas no mercado. O dinamismo e a ampla oferta de emprego para esses profissionais no mercado com salários altíssimos contribuem para a sua alta rotatividade. Por esse motivo, a retenção desses profissionais se tornou um novo desafio a ser enfrentado pela área de Gestão de Pessoas. Este artigo tem a finalidade de mensurar o impacto que a alta rotatividade desses profissionais ocasiona em três empresas (uma do setor público e duas do setor privado) e de identificar o perfil dos profissionais de tecnologia da informação dessas empresas, visando à compreensão das suas necessidades e motivações dentro do ambiente de trabalho. Por meio de pesquisas de campo, o estudo constatou que esses profissionais estão em busca de segurança, desafios e reconhecimento em seu ambiente de trabalho, além de possibilitar fazer a distinção entre os profissionais de tecnologia da informação, do funcionalismo público e do funcionalismo privado.

Palavras-chave: UniCEUB. Retenção. Motivação. Perfil profissional. TIC.

\begin{abstract}
The adaptation to different environments and the search for the development of innovative solutions made of IT professionals sufficient to allow the market continuity of companies. The dynamism and broad jobs opportunities for these professionals in the market with high salaries contribute to its high turnover. Therefore, the retention of these professionals has become a new challenge to be faced by the HR Management. This article is intended to measure the impact that the high turnover of these professionals brings in three companies (one public sector and two private sector) and to identify the profile of information technology professionals in these companies, in order to understand their needs and motivations within the workplace. Through field research study found that these professionals are seeking security, challenges and recognition in their work environment, and enables to distinguish between information technology professionals, the civil service and the private servants.
\end{abstract}

Keywords: UniCEUB. Retention. Motivation. Professional profile. ICT. 


\section{Introdução}

A Tecnologia da Informação se tornou imprescindível para as organizações, podendo impactar, diretamente, no sucesso empresarial e, até mesmo, na continuidade dos negócios. Por esse motivo, as organizações precisam ter, em seu quadro funcional, profissionais de TI qualificados e motivados, para que, assim, possam aproveitar as oportunidades trazidas pela evolução da tecnologia criando diferenciais competitivos que destacam a empresas de seus concorrentes. Completando esse quadro, a área de Gestão de Pessoas deixou de ser, apenas, um setor administrativo de gestão de pessoal para se tornar um setor estratégico da organização, principalmente quando envolve as tarefas de recrutamento, seleção e desenvolvimento de equipes de tecnologia.

O colaborador deixou de ser, apenas, uma ferramenta e um recurso da organização, passando a ser visto, também, como um parceiro da estratégia empresarial. Paralelamente a essa exigência, temos uma nova geração de profissionais chegando ao mercado. Essa geração é reconhecida por seu dinamismo, objetividade, criatividade e sede por desafios e novidades, muito oposto do perfil profissional tradicional.

A área de Gestão de Pessoas assume a responsabilidade de fazer a intermediação entre a empresa e os seus profissionais, tendo como principal objetivo alinhar os interesses individuais com os objetivos, interesses e cultura da empresa, sem que nenhuma das partes seja prejudicada.

Conforme Gil (2001), a Gestão de Pessoas é a área gerencial que tem a finalidade de viabilizar a cooperação entre as pessoas que atuam nas organizações para que sejam atingidos tantos os objetivos tanto organizacionais quanto os individuais.

Segundo Chiavenato (2004), os empregados são considerados os parceiros mais íntimos que as empresas possuem, pois, são os responsáveis por dar vida, energia e dinamismo para elas. São assim considerados como diferencial competitivo das empresas. Em contrapartida, as empresas são consideradas indispensáveis para que os empregados possam atingir os seus objetivos individuais, gerando, assim, uma relação de dependência mútua entre ambos.

Ainda segundo Chiavenato (2004), a Gestão de Pessoas é fundamentada em três aspectos, são eles: a) o empregado como um indivíduo único, dotado de perso- nalidade própria, b) o empregado sendo um impulsionador da organização e c) o empregado como um parceiro da organização, conduzindo-a à excelência.

A valorização das relações humanas no ambiente de trabalho surgiu da constatação de que os fatores psicológicos e sociais influenciavam na produtividade dos funcionários. Esses estudos foram, inicialmente, desenvolvidos pelo psicólogo americano Elton Mayo (1927).

Para Gil (2001), a percepção da importância do profissional no ambiente corporativo proporcionou o surgimento da ideologia da harmonização entre capital intelectual e trabalho definida pelos teóricos da Administração Científica. Essa percepção contribui para o surgimento do processo de integração dos indivíduos dentro das organizações, proporcionando, assim, melhores resultados tanto para as empresas quanto para os funcionários que tiveram suas necessidades sociais e psicológicas satisfeitas.

\subsection{Motivação do profissional}

Conforme foi publicado na "The Communications of the ACM (CURTIS et al., 1988 apud SOUZA, 2004), foi perguntado aos vice-presidentes de engenharia das três maiores empresas de Tecnologia quais fatores são considerados mais importantes para que um projeto de software ser bem-sucedido. As respostas indicaram os profissionais envolvidos como sendo os responsáveis pelo sucesso do projeto e demonstrou que a qualidade do sistema de informação depende da técnica adotada e da motivação dos profissionais envolvidos.

Ainda segundo Gil (2001), a motivação é a força que estimula as pessoas a agir. A motivação origina-se com base em uma necessidade, em que cada indivíduo possui motivações próprias que são geradas por necessidades distintas, e, quando satisfeitas, tendem a perder a força. O comportamento humano é reflexo do desejo do indivíduo em atingir um determinado objetivo, que, muitas vezes, é desconhecido pelo próprio indivíduo.

Várias teorias de motivação profissional foram propostas no século XX para explicar e sistematizar os fatores que levam os colaboradores a serem mais ou menos comprometidos com a empresa e com seu trabalho. De acordo com Robbins (2009), Maslow definiu em sua teoria que as necessidades humanas são dividias em níveis hierárquicos, em que, quando uma necessidade é suprida, a outra se torna dominante, e nenhuma necessidade poderá ser, completamente, satisfeita. 
Na interpretação de Bergamini (2008), os cinco níveis hierárquicos de Maslow são:

- Necessidades Fisiológicas: dizem respeito à sobrevivência do organismo. (Fome, vestimenta, abrigo, sono, sexo etc.).

- Necessidades de Segurança: busca encontrar um ambiente livre de ameaças. (Medo de ser demitido, ambiente físico seguro).

- Necessidades Sociais: voltada à aceitação e amizade no grupo (se sentir aceito pelos outros).

- Necessidades de Estima: direcionada à busca de uma imagem positiva de si mesmo. (Amor próprio e respeito dos outros).

- Necessidades de Auto Realização: busca pela individuação, ou seja, atingir o seu potencial máximo como indivíduo. (Realização pessoal).

Para Gil (2001), as pessoas não são motivadas por recompensas financeiras. Para motivá-las, os gestores das empresas precisam conhecer melhor a personalidade de seus colaboradores e, por meio desse conhecimento, elaborar medidas que visam proporcionar uma melhor satisfação de suas necessidades.

Na visão de Rocha (1997), McGregor classificou, em sua teoria, os colaboradores em dois grupos distintos. O primeiro grupo é dos colaboradores que não gostam de trabalhar, e que, executam suas tarefas por meio de ordens. Os colaboradores do primeiro grupo, geralmente, são motivados por recompensas financeiras. Já os colaboradores do segundo grupo são motivados pela possibilidade de crescimento profissional e pessoal. Essa teoria, segundo Robbins (2009), propõe duas visões distintas sobre o comportamento humano. A primeira visão é denominada de teoria $\mathrm{X}$, em que são ressaltados os pontos negativos dos colaboradores. A segunda visão é denominada de teoria $Y$, em que são ressaltados os pontos positivos dos colaboradores.

Teoria X - Os indivíduos, por natureza, não gostam de trabalhar e, sempre tentam evitar o trabalho; Como eles não gostam de trabalhar, precisam ser coagidos, controlados ou ameaçados com punições para que atinjam as metas; Os funcionários evitam responsabilidades e buscam orientação formal sempre que possível; A maioria dos trabalhadores coloca a segurança acima de todos os fatores associados ao trabalho e demonstram pouca ambição.

Teoria Y - Os indivíduos podem achar o trabalho algo tão natural quanto descansar ou di- vertir-se; As pessoas demonstrarão auto-orientação e autocontrole, se tiverem comprometidas com os objetivos; Na média, as pessoas podem aprender a aceitar, ou até buscar, a responsabilidade; Qualquer pessoa pode ter capacidade de tomar decisões inovadoras. Não se trata de privilégio exclusivo daquelas em posições hierárquicas mais altas. (ROBBINS, 2009, p. 50).

Ainda segundo Robbins (2009), a Teoria dos Dois Fatores de Herzberg foi desenvolvida por meio de um levantamento acerca de como o indivíduo se sente nas mais diversas situações de trabalho. Pode-se concluir que os pesquisados que se sentiam bem no trabalho relacionavam esse fato a eles mesmos. Enquanto os que se sentiam insatisfeitos atribuíam esse fato a fatores externos, como as condições de trabalho.

Para Bergamini (2008), a teoria de Herzberg demonstrou que a motivação ocorre por meio de dois fatores diferentes, os que trazem satisfação e os que causam insatisfação. Os fatores que causam satisfação ao indivíduo são considerados intrínsecos e que, em sua ausência, não causa insatisfação. E os fatores que causam insatisfação ao indivíduo são considerados extrínsecos, ou seja, a sua presença não causa satisfação, mas a sua ausência causa insatisfação.

Para Kessler (2006), Herzberg concluiu que alguns pontos utilizados por ele são utilizados por Maslow em sua Teoria de Necessidades, que diz que os indivíduos são, sempre, motivados por fatores internos (motivacionais), mas se opôs ao classificar os fatores externos (de higiene) como sendo, apenas, fatores que não estimulam o indivíduo.

Nas palavras de Bergamini (2008), os dois fatores de Herzberg são:

- Fatores de Higiene (insatisfação): remuneração, condições de trabalho, segurança, supervisão e relação com subordinados.

- Fatores de Motivação (satisfação): reconhecimento, realização, progresso, o trabalho em si e o seu desenvolvimento como profissional.

Para Robbins (2009), aumentar a remuneração de um profissional com o intuito de eliminar a insatisfação não o fará mais motivado. Herzberg sugere, então, que os executivos deem ênfase em métodos voltados para a motivação interior de seus funcionários, como por exemplo, o reconhecimento pelo trabalho executado de seus funcionários.

Em 1964 foi desenvolvida uma nova teoria pelo psicólogo Victor Vroom que, segundo Rocha (1997), re- 
laciona a motivação das pessoas com três pontos: o esforço, o desempenho e a recompensa. O esforço exercido pela pessoa será o seu desempenho que será recompensado. A recompensa poderá ser intrínseca ou extrínseca.

Para Scianni (2005), a sua Teoria de Expectativas reconhece que não existe um princípio universal que propiciara a motivação nas pessoas. A teoria se sustenta na filosofia de que todas as pessoas executam algum tipo de atividade esperando obter, sempre, algo em troca. Que o esforço e o desempenho utilizado para a execução de determinada atividade serão recompensados, tanto para os objetivos da empresa, quando para os seus objetivos pessoais.

A teoria desenvolvida pelo psicólogo Edwin Locke, na década de 1960, descrita por Scianni (2005), parte do princípio da motivação por meio do estabelecimento de metas e objetivos. Ainda segundo a autora, a teoria se baseia na definição de metas que os profissionais deverão atingir. A teoria possui fortes impactos nas avaliações de desempenho e de produtividade.

\subsection{Rotatividade}

Para Chiavenato (2004), a rotatividade é o efeito ocasionado por fenômenos internos ou externos das organizações que influenciam no comportamento dos colaboradores. Ainda segundo o autor, o desligamento por iniciativa do colaborador está relacionado à motivos pessoais e profissionais, ou seja, quando o colaborador se sente desmotivado com o serviço executado ou quando este recebe uma oportunidade melhor fora da empresa em que atua.

Conforme Mobley (1992 apud BORGES, 2011), o administrador de recursos humanos deve ser capaz de diagnosticar a natureza e as causas dos altos índices de rotatividade, avaliar quais as suas consequências nas empresas e desenhar políticas, práticas e programas que visam diminui-lo.

Segundo Pontes (2001 apud ECKERT, 2011), a rotatividade dos funcionários está relacionada, diretamente, com a falta de planejamento no momento de sua admissão. Segundo o autor, havendo um planejamento bem-estruturado e um investimento por parte da empresa em programas de desenvolvimento e treinamento para seus colaboradores, com o intuito de promovê-los, pode-se diminuir o número de funcionários desligados.

Segundo Foina (2012), a demissão de um profissional em uma empresa acarreta a perda do Conhecimen- to Tácito, ou seja, aquele que o profissional possui em seu cérebro e que, muitas vezes, não é documentado.

Para Chiavenato (2004), os custos relacionados com o desligamento de um profissional podem ser definidos em três tipos de custos: os custos primários, os custos secundários e os custos terciários. Os custos primários são aqueles ligados à substituição do colaborador (recrutamento e seleção, publicidade, entrevistas, registro do profissional, custo com a documentação e com formulários, custos rescisórios, multas rescisórias, entrevistas de desligamento, entre outros). Os custos secundários são aqueles com reflexos de curto prazo (perda de produtividade, desmotivação da equipe, custos com as horas extras que os colaboradores terão que fazer para suprir com as tarefas do colaborador desligado, entre outros). Finalmente, os custos terciários são aqueles que são percebidos em médio e em longo prazo (aumento da taxa de seguros, depreciação de equipamentos e o aumento do salário oferecido, inicialmente, etc.).

Para Mobley (1992 apud BORGES, 2011), uma das vantagens da rotatividade é que, com a entrada de novos colaboradores, a empresa passa a ganhar novos conhecimentos, novas visões e novas ideias.

Ainda segundo Mobley (1992 apud FRANCO, 2010), um dos grandes pontos negativos oriundos da alta rotatividade de profissionais vem do impacto que a falta desses profissionais considerados estratégicos ocasionará para o cumprimento dos projetos da empresa, podendo acarretar no seu adiamento ou no seu cancelamento, proporcionando, assim, prejuízos financeiros.

\section{Estudo de casos}

\subsection{Empresa 1}

A EMPRESA 1 surgiu como o resultado de um projeto inovador que, ao final da década de 90, disponibilizou à sociedade um portal de cursos online. O sucesso do projeto fez com que os executivos da empresa se atentassem para a educação a distância como um novo nicho de mercado. Conta, atualmente, com mais de 240 colaboradores em quatro unidades localizadas em quatro estados da União.

Nessa empresa foram aplicados questionários para $78 \%$ dos colaboradores do setor de tecnologia na sua filial de Brasília, em que, aproximadamente, $80 \%$ dos profissionais que compõem o setor de tecnologia são do sexo masculino. 
Os colaboradores dessa empresa procuram um emprego em que possam encontrar equilíbrio pessoal e profissional. São precavidos em relação aos riscos do mercado de trabalho, ponderam antes de aceitar uma oferta de emprego, mesmo que a remuneração oferecida seja um pouco melhor. Estariam dispostos a trocar de emprego se o salário oferecido fosse no mínimo 30\% acima de seus salários atuais.

Eles, também, procuram um trabalho dinâmico e desafiador, onde possam ter a possibilidade de criar e aprender coisas novas. Buscam desenvolver soluções inovadoras e estão dispostos a realizar cursos de aperfeiçoamento e capacitação, mesmo que esses cursos sejam fora do seu horário de trabalho.

Esses profissionais não se sentem confiantes para adotarem o trabalho remoto (home office). Eles acreditam não serem capazes de administrar o seu tempo da forma com que possam produzir mais trabalhando em casa, mas, por outro lado, gostariam de ter um emprego onde pudessem acordar mais tarde.

Eles acreditam que o trabalho que realizam contribui para o desenvolvimento da comunidade onde vivem, além de poder influenciar as decisões da empresa. Seus familiares têm conhecimento e orgulho do trabalho que executam.

Disseram, ainda, receber os equipamentos necessários para realizar suas tarefas e estão dispostos a dar mais de si para concluir um trabalho. Acreditam que o volume de trabalho é um fator irrelevante, além de acharem que um cargo de chefia não representaria um sucesso profissional.

Os colaboradores se sentem bem aceitos em seu ambiente de trabalho e levariam em consideração as pessoas que trabalham na empresa e, principalmente, sua equipe antes de aceitarem uma oferta de emprego ou mudança de função. Sentem, também, que seus superiores reconhecem os serviços que prestam para a empresa, além de acharem que são informados sobre as mudanças que ocorrem na empresa e nos negócios.

$\mathrm{Na}$ visão deles, o clima organizacional e reconhecimento profissional são fatores importantes para a sua permanência na empresa e a ausência desses fatores ser desmotivador para eles. Estão dispostos a indicar seus amigos para trabalharem na empresa. Acham que as campanhas motivacionais promovidas pela empresa não geram os resultados esperados, pois, não são capazes de reter os colaboradores.
Quando perguntados qual a empresa/organização possui o modelo de ambiente de trabalho que os colaboradores gostariam de ver sendo aplicados, eles citaram a Google, como referência de empresa.

\subsection{Empresa 2}

A EMPRESA 2 é um órgão do Governo Federal responsável por assistir, direta e imediatamente, ao Presidente da República quanto aos assuntos que, no âmbito do Poder Executivo, sejam relativos à defesa do patrimônio público e ao incremento da transparência da gestão, por meio das atividades de controle interno, auditoria pública, correição, prevenção e combate à corrupção e ouvidoria.

O estudo foi realizado com base nas respostas fornecidas por meio da aplicação de questionários a $41 \%$ dos servidores da sede do órgão em Brasília.

Os servidores dessa empresa não possuem tanta preocupação em relação ao mercado de trabalho, tendo em vista o seu regime de contratação (estatutários). Por esse motivo, estariam dispostos a aceitar uma proposta de emprego que oferecesse a mesma remuneração, mas que propiciasse mais benefícios, o que leva a uma grande concorrência entre os órgãos governamentais.

Os servidores pontuaram o equilibro pessoal e profissional como sendo o ponto mais relevante no momento em que estão procurando um emprego. Ficaram divididos quando perguntados se pensariam duas vezes antes de aceitar uma proposta cuja remuneração financeira fosse um pouco melhor. Estariam dispostos a aceitar uma oferta de mudança de emprego por qualquer pequeno aumento de salário (entre $0 \%$ a $25 \%$ acima do seu salário atual).

Eles, também, procuram por um emprego em que possam desenvolver soluções inovadoras, o que demonstra que gostam de serviços desafiadores. Acreditam que um cargo de chefia não representaria o seu sucesso profissional.

Os servidores dessa organização se sentem confiantes para aderirem ao trabalho remoto (home office), pois acreditam serem capazes de administrar o seu tempo de forma a otimizar a sua produção. Por outro lado, não consideram a possibilidade de acordar mais tarde como ou benefício no seu trabalho.

Apesar do trabalho que executam estar diretamente ligado ao atendimento das necessidades dos cidadãos, não creem que o seu trabalho contribui para o desenvol- 
vimento da comunidade em que vivem. Não acreditam, ainda, terem poder para influenciar as decisões da empresa, apesar de acharem que esses fatores sejam relevantes para qualquer emprego.

Metade dos servidores disse que os seus familiares têm consciência do local onde trabalham e sentem orgulho do trabalho que realizam, mesmo sendo essa opinião considerada irrelevante para eles.

Os servidores disseram receber os equipamentos necessários para a realização dos seus afazeres. Disseram, ainda, estarem dispostos a dar mais de si para concluírem um trabalho, mas ficaram divididos ao responderem se o volume e o trabalho executado seriam levados em consideração no momento de decidirem aceitar um novo emprego.

Disseram, ainda, estarem dispostos a realizar cursos de capacitação a aperfeiçoamento visando ao acréscimo em seus salários, sem avaliarem o impacto desses cursos no crescimento da empresa. Um pouco mais da metade deles disse estar disposta a fazer cursos fora do seu expediente visando ao crescimento da empresa.

Os servidores dessa empresa se sentem bem aceitos em seu ambiente de trabalho. Mas a metade deles disse que não levaria as pessoas e a sua equipe em consideração no momento de aceitar uma oferta de emprego ou de mudança de função, pois não considera isso um fator relevante. Estariam dispostos a indicar seus amigos para trabalharem na empresa.

Na visão desses servidores, o reconhecimento profissional e o clima organizacional são pontos considerados relevantes para a sua permanecia na empresa. Eles, também, disseram não acreditar que as campanhas motivacionais promovidas por sua empresa sejam capazes de reter os servidores. Quando perguntados qual a empresa/ organização possui o modelo de ambiente de trabalho que os colaboradores da EMPRESA 2 gostariam de ver sendo aplicados, eles citaram o Tribunal de Contas da União (TCU).

\subsection{Empresa 3}

A EMPRESA 3 é uma das maiores empresas privadas de Teste e Qualidade de Software. Possui mais de 900 funcionários e conta com escritórios em três estados da União para atender todo o território nacional. Foi aplicado questionário em mais de $45 \%$ dos colaboradores da unidade de Brasília. consigam se sentir especiais e, ao mesmo tempo, possuir um equilíbrio pessoal e profissional. São precavidos em relação aos riscos do mercado, pois disseram ponderar muito antes de aceitarem uma oferta de emprego, mesmo que a oferta em questão ofereça uma remuneração financeira um pouco melhor. A maioria só estaria disposta a trocar de emprego se a remuneração oferecida fosse no mínimo 30\% acima da que recebem atualmente.

Eles, também, procuram um emprego onde consigam ter a oportunidade de desenvolver soluções inovadoras e ao mesmo tempo aprender coisas novas. Estariam dispostos a realizar cursos de capacitação e aperfeiçoamento fora do seu horário de trabalho visando contribuir com o crescimento da empresa, independentemente de ganharem ou não aumento de remuneração.

Disseram, ainda, serem capazes de administrar o seu tempo de forma a apresentar resultados favoráveis trabalhando remotamente, mas que, ainda assim, não gostariam de aderir ao trabalho remoto e nem estariam dispostos a condicionar a aceitação de um emprego, apenas, em função do horário de início da jornada de trabalho.

Esses profissionais acreditam que o trabalho que realizam influencia nas decisões da empresa, além de contribuir para o desenvolvimento da sociedade em que vivem. Seus familiares têm conhecimento e orgulho do trabalho que executam.

Disseram, também, que o trabalho que executam seria um ponto importante a ser observado na hora de aceitar um emprego, mas que o volume de trabalho não influenciaria em sua decisão e que estariam dispostos a dar mais de si para concluir um trabalho. Acreditam, ainda, receber os equipamentos necessários para tocar com seu trabalho e que não consideram o cargo de chefia como sendo seu sucesso profissional.

Disseram se sentir bem aceitos em seu ambiente de trabalho e que levariam em consideração seus colegas de empresa, além da sua equipe de trabalho, em consideração antes de aceitarem uma oferta de emprego ou uma mudança de função.

Também acreditam que seu trabalho é reconhecido por seus superiores e acham que são informados por eles sobre as mudanças ocorrem na empresa e n mercado.

$\mathrm{Na}$ visão desses colaboradores, o reconhecimento profissional não seria um fator capaz de desmotiva-los, mas que o clima organizacional seria capaz de influenciar em sua permanência na empresa. Eles, também, acham que as campanhas motivacionais promovidas pela em- 
presa não são capazes de reter os colaboradores, mas estariam dispostos a indicar seus amigos para trabalharem na empresa. Os colaboradores da EMPRESA 3 possuem um perfil dinâmico e colaborativo. São profissionais engajados com a realização dos seus objetivos pessoais e com os objetivos da empresa. Consideram o clima organizacional, a comunicação e os seus relacionamentos com seus colegas de trabalho e seus superiores um fator imprescindível para sua permanecia na empresa. Elencaram também o Google como empresa de referência no quesito ambiente de trabalho.

\section{Conclusão}

Concluímos que a alta rotatividade de profissionais dentro das organizações pesquisadas é proveniente da falta de um planejamento estratégico para a admissão e retenção desses profissionais. Essa rotatividade acarreta prejuízos monetários e não monetários, que vão desde a perda de recursos financeiros decorrentes de rescisões e multas contratuais até a perda de conhecimento intelectual (tácito) da equipe que pode trazer impactos no curto, médio e longo prazo.

Foi possível observar divergências e semelhanças entre o perfil dos profissionais de T.I das empresas pesquisadas que merecem um aprofundamento em outros estudos posteriores. Na empresa do setor público, os servidores de T.I são focados mais nas suas realizações pessoais, sem levar em consideração os objetivos do órgão ou seus colegas de trabalho. Enquanto que nas empresas do setor privado os colaboradores possuem uma visão de parceria entre empresa e funcionário. Além de serem mais precavidos com os riscos do mercado.

Todos os profissionais de tecnologia da informação pesquisados anseiam por um emprego que lhes propicie estabilidade pessoal e profissional, e sentem-se motivados por trabalhos que estimulem seus talentos. Em sua maioria, não possuem interesse em trabalhar remotamente, mesmo sendo capazes de administrar seu tempo. Possuem uma percepção em relação à influência que ocasionam na sociedade e na empresa em que atuam.

$\mathrm{O}$ ambiente de trabalho e a cultura organizacional impactam, diretamente, em sua aceitação ou permanecia na empresa. Todos se sentem aceitos por seus superiores e por sua equipe. Além disso, esses profissionais creem que as campanhas motivacionais promovidas por suas empresas não resultam nos objetivos nos quais foram criadas. Os colaboradores de tecnologia das empresas privadas apontaram a empresa de serviços online Google como sendo seu referencial no que se refere ao ambiente de trabalho ideal, enquanto os profissionais dos órgãos públicos escolheram o Tribunal de Contas da União (TCU).

Esperamos que esse estudo tenha contribuído para uma melhor compreensão acerca desse novo perfil profissional que tem se destacado dentro do ambiente corporativo, visando aperfeiçoar a Gestão de Pessoas para um melhor aproveitamento dos seus talentos e a diminuição da rotatividade.

\section{Referências}

BERGAMINI, Cecília Whitaker. Motivação nas organizações. São Paulo: Atlas, 2008.

BORGES, Mara Santos et al. Turnover: uma consequência de estratégias ineficientes de gestão empresarial? Monografia, 2011. Disponível em: <http://www.convibra.com. br/upload/paper/adm/adm_2784.pdf $>$. Acesso em: 05 fev. 2015.

CHIAVENATO, Idalberto. Gestão de pessoas: e o novo papel dos recursos humanos nas organizações. Rio de Janeiro: Elsevier, 2004.

CUNHA, Joanna Maia Carneiro da. A influência da qualidade de vida no trabalho na motivação dos funcionários do Serpro. Monografia. Brasília, 2008. Disponível em: <http://www.repositorio.uniceub.br/bitstream/123456789/948/2/20451270.pdf>. Acesso em: 27 fev. 2015.

ECKERT, Alex et al. As motivações e os reflexos do turnover em termos contábeis e econômicos numa entidade sem fins lucrativos do município gaúcho de Caxias do Sul. Monografia. Caxias do Sul, 2011. Disponível em: <http://unisc. br/portal/upload/com_arquivo/tc13_3279951870050. pdf $>$. Acesso em: 23 maio 2015.

FOINA, Paulo Rogério. Tecnologia de informação: planejamento e gestão. São Paulo: Atlas, 2012.

FRANCO, Eliane Soares Mendes et al. Turnover e a gestão estratégica de pessoas: superando a cultura da rotatividade de pessoal. 2010. Disponível em: <http://www.diferencialmg.com.br/site/images/artigos/turnover-autalizado-dezembro-2010.pdf>. Acesso em: 06 fev. 2015. 
GIL, Antônio Carlos. Gestão de pessoas: enfoque nos papéis profissionais. São Paulo: Atlas, 2001.

KESSLER, Laureno José. Pesquisa motivacional: uma análise comparativa na Eletronorte. Monografia. Brasília, 2006. Disponível em: <http://www.repositorio.uniceub. br/bitstream/123456789/866/2/20301298.pdf>. Acesso em: 18 nov. 2014.

ROBBINS, Sthepen Paul. Fundamentos do comportamento organizacional. São Paulo: Person Prentice Hall, 2009.

ROCHA, J. A. Oliveira. Gestão de recursos humanos. Lisboa: Presença, 1997.
SCIANNI, Virgínia. Motivação organizacional: teorias e práticas nas organizações. Monografia. Brasília, 2005. Disponível em: <http://repositorio.uniceub.br/bitstream/123456789/736/2/20051560.pdf>. Acesso em: 27 fev. 2015.

SOUZA, Enock Godoy de. Cultura e motivação dos profissionais de tecnologia da informação no Brasil. São Paulo, 2004. Disponível em: <http://www.ead.fea.usp.br/ Semead/7semead/paginas/artigos\%20recebidos/mqi/ MQI05_-_Cultura_e_Motiva\%E7\%E3o_dos_profissionais_.PDF>. Acesso em: 25 fev. 2015. 